\title{
Rickets with Alopecia Signals Vitamin D Dependent Rickets Type II
}

\author{
Yadav SP ${ }^{1}$, Bhatta NK $^{2}$
}

\begin{abstract}
Vitamin D-dependent rickets type II is a rare autosomal recessive disorder. We report 27 months female child with classical rachitic changes, very high level of 25 -hydroxy Vitamin $D, 1,25$ $(\mathrm{OH})_{2} \mathrm{D}$ and markedly elevated serum Alkaline phosphatase. Very high dose of oral calcium and vitamin $\mathrm{D}_{3}$ was prescribed with minor improvement in skeletal features and alopecia. This case report hints the physician to diagnose and manage Vitamin D-dependent rickets type II, when rachitic changes are associated with alopecia.
\end{abstract}

Key words: Rickets, Vitamin D, 25-Hydroxyvitamin $\mathrm{D}_{3}$, 1-alphaHydroxylase deficiency

\section{Introduction}

$\mathrm{P}$ atients with vitamin $\mathrm{D}$ dependent rickets (VDDR) type 2 have mutations in the gene encoding the vitamin $D$ receptor, preventing a normal physiologic response to 1,25-D. The mode of inheritance is autosomal recessive. Most patients present during infancy, although rickets in less severely affected patients might not be diagnosed until adulthood. Less-severe disease is associated with a partially functional vitamin D receptor. Approximately $50-70 \%$ of children have alopecia, which tends to be associated with a more severe form of the disease. ${ }^{1}$ The intriguing disease generally presents with a clinical picture of rickets, hypocalcaemia, hypophosphatemia, growth retardation, hyperparathyroidism along with extremely elevated circulating levels of $1,25(\mathrm{OH})_{2}$ D. ${ }^{2}$ Resource poor countries, where estimation of parathyroid hormone and $1,25(\mathrm{OH})_{2} \mathrm{D}$ are not readily available, alopecia in the setting of resistant rickets could be an important cue for the diagnosis of this rare condition. ${ }^{3}$ Since the time, Brooks, et al reported the first case in $1978,{ }^{4}$ only few cases have been reported in the world literature. We report one such case with alopecia.

\section{The Case}

A 27 months old female child presented with acute respiratory illness. This was her first visit to our department. On history we found that she had delayed gross motor development milestones as she started standing without support at 24 months and at 27 months she could just walk with unstable gait. She had short
'Dr. Shankar Prasad Yadav, Assistant Professor, ${ }^{2}$ Prof. Dr. Nisha Keshary Bhatta, Professor. Both from the Department of Paediatrics, B.P. Koirala Institute of Health Science, Dharan, Nepal.

\section{Address for correspondence:}

Dr. Shankar P Yadav

E-mail: shankardharan@gmail.com

\section{How to cite}

Yadav SP, Bhatta NK. Rickets with Alopecia Signals Vitamin D Dependent Rickets Type II. J Nepal Paediatr Soc 2015;35(2):198-201.

doi: http://dx.doi.org/10.3126/jnps.v35i2.13129

This work is licensed under a Creative Commons Attribution 3.0 License.

\section{(c) (i)}

stature and lack of hair on scalp. Family history revealed that she was born of nonconsanguineous marriage. She had two elder sisters; the eldest one was alive and healthy while the other died at 6 years. No medical consultation was obtained for the deceased child but she has features similar to the case being reported.

The personal history of our index case depicted that she had uneventful prenatal, natal and post-natal period.The child has normal teeth eruption but her anterior fontanelle was open. On examination she has classical features of craniotabes, frontal bossing, pigeon chest, Harrison groove, bow legs, knock knees and widening of wrists and ankles (Fig. 1).

She has diffuse alopecia also. On anthropometric examination, her head circumference was $45.5 \mathrm{~cm}$, between -2 to -3 z score. Her weight was $12 \mathrm{~kg}$, normal for 
age and height of $84 \mathrm{~cm}$ between -2 and $-3 \mathrm{z}$ score. No abnormality was detected on systemic examination of cardiovascular, gastrointestinal and central nervous system examination. On view of systemic manifestation of rickets and alopecia VDDR type II rickets was suspected. 25-hydroxy Vitamin D level was $86.4 \mathrm{ng} / \mathrm{ml}$ (normal 30.0-74.0 ng/ml) and 1,25 $(\mathrm{OH})_{2} \mathrm{D}$ was found to be $445 \mathrm{pg} / \mathrm{ml}$ (normal 19.6 to $75 \mathrm{pg} / \mathrm{ml}$ ). Serum Alkaline Phosphatase level was 2163 IU (markedly raised), total calcium level of $8.4 \mathrm{mg} / \mathrm{dl}(9-11 \mathrm{mg} / \mathrm{dl})$, Phosphorus level of $2 \mathrm{mg} / \mathrm{dl}(4.5-6.7 \mathrm{mg} / \mathrm{dl})$ and serum creatinine level of $0.5 \mathrm{mg} / \mathrm{dl}$.
X-Ray of wrist and knee revealed metaphyseal widening, fraying, cupping, decrease bone density and bowing of long bones suggestive of rickets (Fig. 2).

High doses of Vitamin $D_{3}$ and calcium were started. Vitamin D3 was prescribed in dose of 60,000 IU(1500mcg) per day and oral calcium of1800 mg per day, much above the daily requirements. After six months of follow- up, we observed that the physical, biochemical and radiological features showed mild improvement and sparse hair growth was noticed on the scalp (Fig. 3).

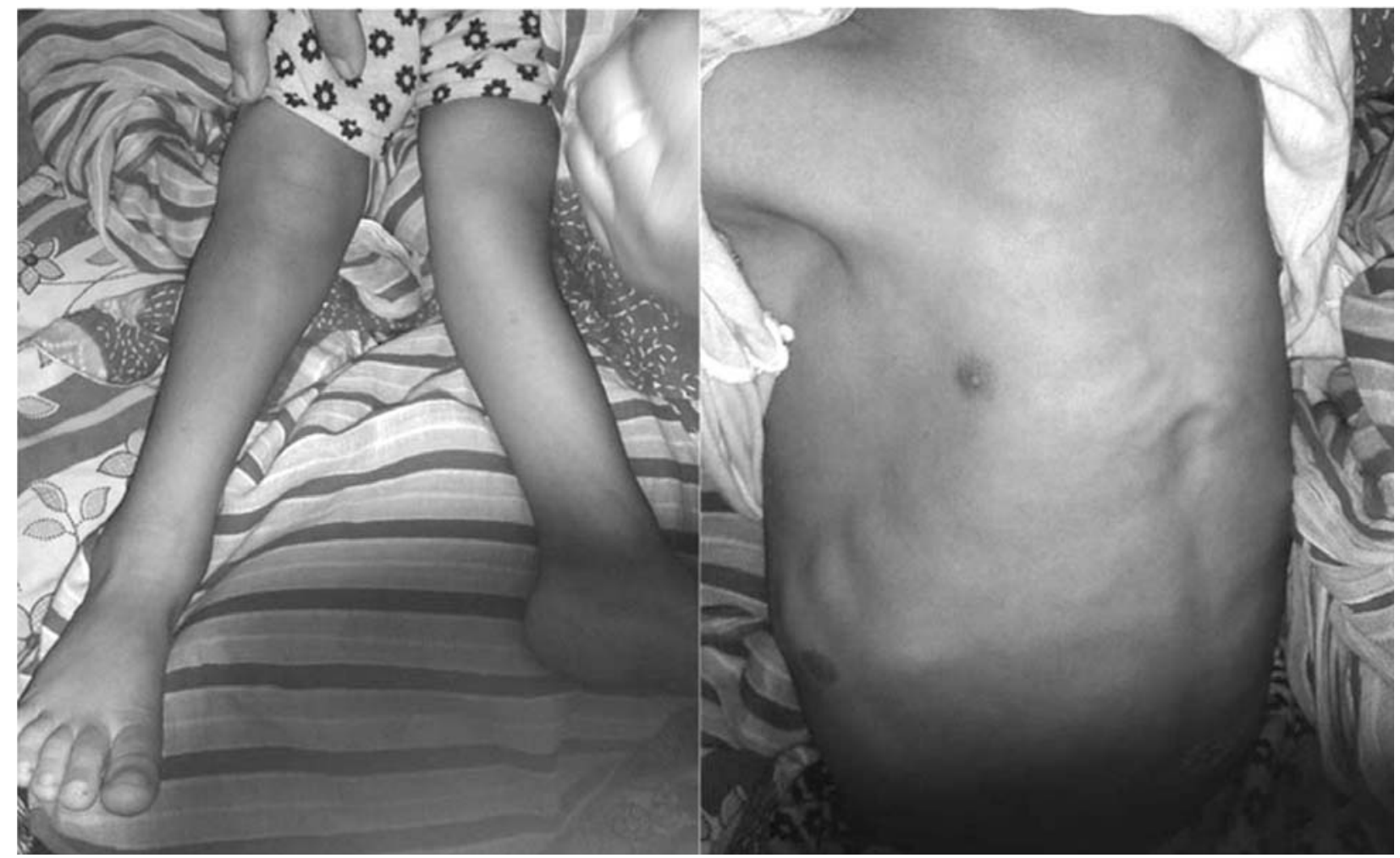

Fig 1: Picture showing knock knees, bow legs, pigeon chest, Harrison groove

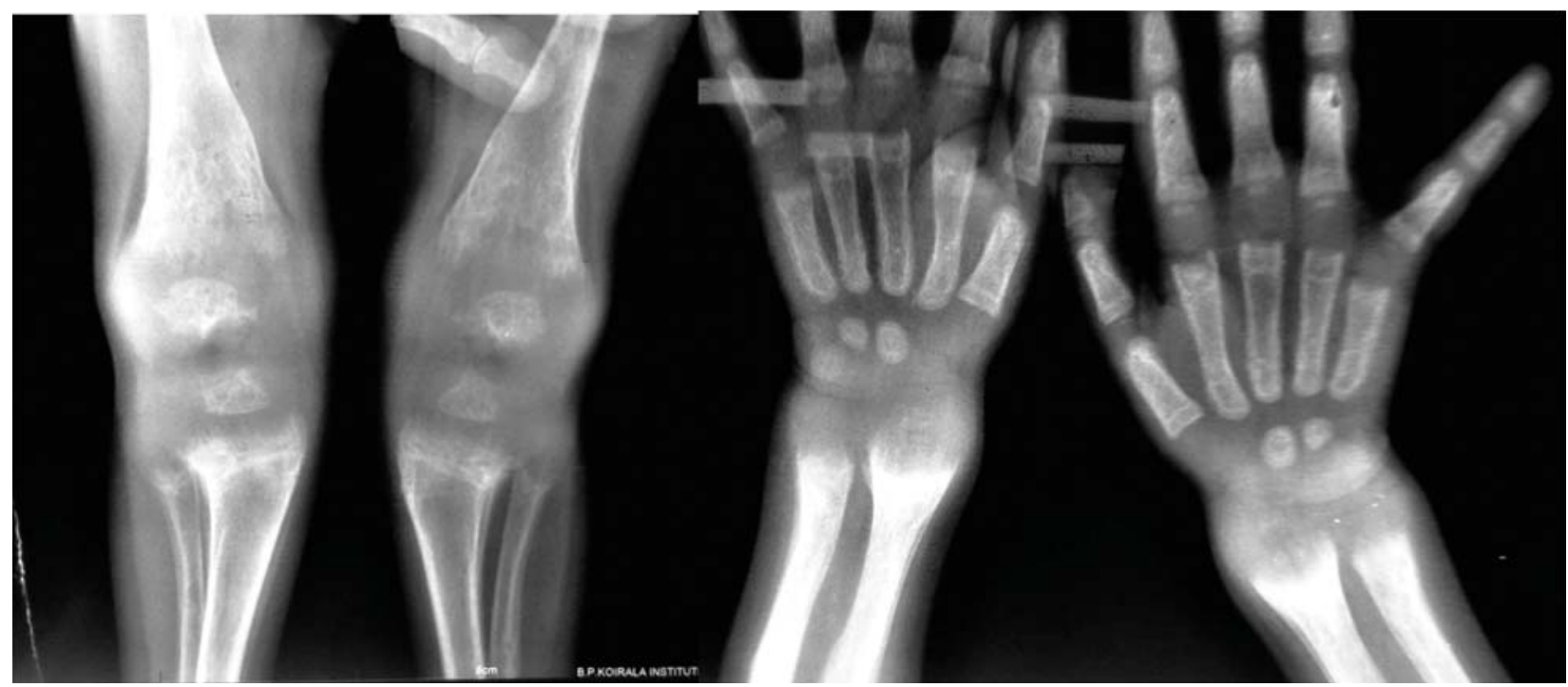

Fig 2: X-ray showing metaphyseal widening, cupping, fraying and splaying. 


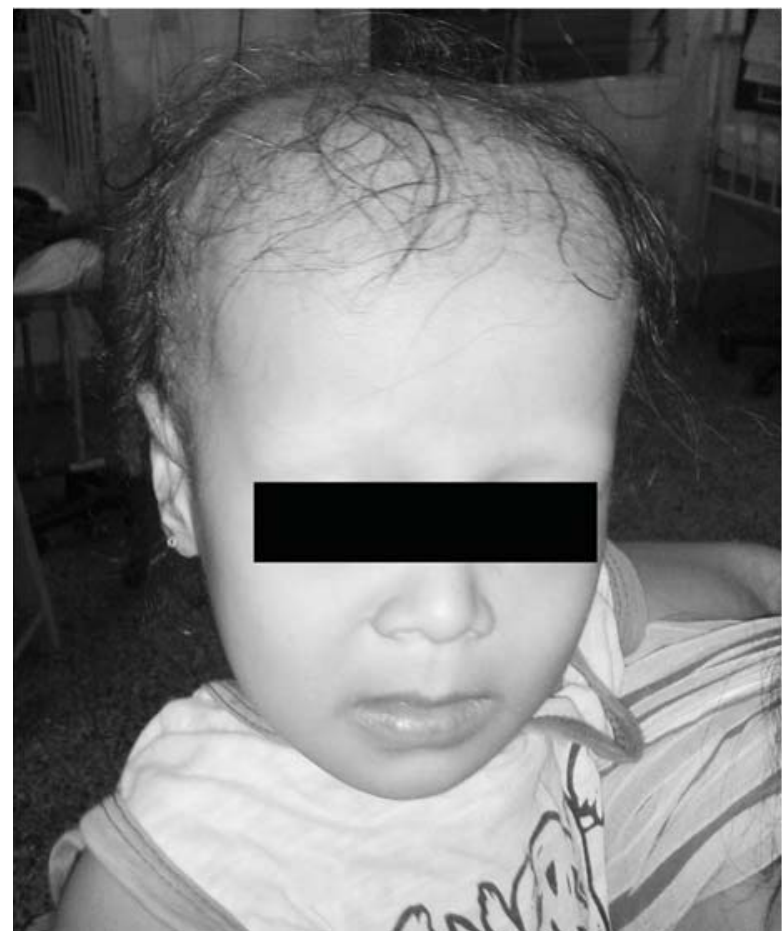

Fig 3: Hair growth over scalp after Vitamin $D_{3}$ and Calcium therapy

\section{Discussion}

Vitamin D-dependent rickets Type II is a rare autosomal recessive disorder. It usually presents with rachitic changes not responsive to Vitamin D treatment withelevated circulating levels of 1,25-Dihydroxyvitamin $D_{3}$, thus differentiating it from Vitamin D-dependent rickets Type I. Alopecia of the scalp or the body is seen in some families with Vitamin D-dependent rickets Type II. This is usually associated with more severe resistance to Vitamin D. ${ }^{5}$ The basic defect involves the unresponsiveness of vitamin $D$ receptors to 1,25 dihydroxy vitamin D. ${ }^{6}$ Eilet al demonstrated defective nuclear uptake of 1,25-dihydroxyvitamin D in cultured fibroblasts from these patients. ${ }^{7}$

Different studies indicate the heterogeneous nature of the defects leading to VDDR II. The defect could be an absent ${ }^{8}$, or a truncated ${ }^{9}$ receptor, or a point mutation in the steroid binding domain ${ }^{10}$ or in one of the zinc fingers in the DNA binding domain of the receptor ${ }^{11}$, or still a defective nuclear localisation of hormone receptor complex. ${ }^{12}$ The cause of alopecia is postulated to be the lack of ligand-independent function of the vitamin $D$ receptor in keratinocytes which is necessary for proper anagen initiation (Sakai et al. 2001). ${ }^{13}$

The patient was suspected as VDDR type II with classical presentation of alopecia and clinical feature of rickets and diagnosed by blood and $\mathrm{x}$-ray investigations. The other causes of rickets such as nutritional, malabsorption, drug induced, hepatic, renal and familial hypophosphatemic were excluded on clinical and laboratory evaluation. Presence of high levels of $1,25-(\mathrm{OH})_{2} \mathrm{D}_{3}$ ruled out VDDR type I.

There is no consensus on the treatment of VDDR type II. A case report revealed two siblings with VDDR II with alopecia reported by Takeda et al. (1989) who responded to treatment with 50,000 IU of Vitamin D2, daily for 2 years without any recurrence for 14 years after cessation of therapy. ${ }^{14}$

Balsan et al. (1986) demonstrated healing of rickets by long-term calcium infusions. ${ }^{15}$ Manandhar et al. (1989) reported a child with rickets and alopecia who did not respond to high doses of vitamin $D_{3}$ but did respond to a small dose of 1-alpha-hydroxyvitamin $\mathrm{D}_{3}$. Treatment was continued for 2 years, and the patient did not show any signs of relapse 1 year after stopping treatment. However, the alopecia did not resolve, and she continued to have increased serum 1,25-dihydroxycholecalciferol. ${ }^{16}$

Present case had classical clinical and radiological features of rickets along with alopecia and showed some response to high dosage of Vitamin $D_{3}$ and Calcium. Substantial hair growth was noted after 6 months of treatment. In such type of presentation clinician should always think of vitamin $D$ resistant rickets type II.

\section{Conclusion}

VDDR type II is a rare disorder. In a child with clinical and radiological features pointing towards rickets, presence of alopecia heralds the clinician to think towards this condition. High dosage of oral Vitamin $D_{3}$ and calcium supplementation does show some beneficiary effect.

\section{References}

1. KliegmanRM, Stanton BF, St. Geme III JW, Schor NF, Behrman RE. Nephrology. Chapter 48. In: Nelson Textbook of Pediatrics. 19th ed. Philadelphia: Elsiever Saunders; 2011: 205.

2. Mishra S, YadavTP, Nangia S, Gupta VK, Sidhu KK. Vitamin D dependent rickets type II. Indian Pediatr 1996;33:334-6.

3. Malla K, Malla T, Shaw C, Thapalial A. Type II vitamin D dependent rickets: A case report. J Nepal Paediatr Soc 2010;30:46-9. 
4. Brooks $\mathrm{MH}$, Bell NH, Love L, Stern PH, Orfei E, Queener SF, et al. Vitamin D dependent rickets Type II Resistance of target organs to 1, 25-dihydroxy vitamin D. N Engl J Med 1978;298:996-9.

5. Sultan Al-Khenaizan, Vitale P.Vitamin D-dependent rickets Type II with alopecia: two case reports and review of the literature. Int $J$ Dermato/2003;42(9):682-5.

6. Greenbaum LA,KliegmanRM, Behrman RE, Jenson HB. Rickets and Hypervitaminosis D. In: Nelson Textbook of Pediatrics, 18th ed. Philadelphia: ElsevierSaunders: 2007:253-62.

7. Eil C, Liberman UA, Rosen JF, Marx SJ. A cellular defect in hereditary vitamin $-D$ dependent rickets type II: defective nuclear uptake of 1 , 25-dihydroxyvitamin $D$ in cultured fibroblasts. $N$ Engl J Med 1981;304(26):1588-91

8. Feldman DT, Chen T, Cone $C$, Hirst $M$, Shani $S$,Benderli $A$, et al. Vitamin $D$ resistant rickets with alopecia: cultured skin fibroblast exhibit defective receptors and unresponsiveness to 1,25 (OH), D3. J ClinEndocrinolMetab 1982;55:1020-2.

9. Weise RJ, GotoH, PrahlJM, Marx SJ, Thomas M,alAqeel $A$, et al. Vitamin $D$ dependency rickets type II: Truncated vitamin D receptor in three kindreds. Molecul Cell Endocrinol 1993;90:197-201.

10. Malloy PJ, Hochberg Z, Tiosana D, PikeJW, Hughes MR, Feldman D,et al. The molecular basis of hereditary 1,25- dihydroxy vitamin D3 resistant rickets in seven related families. Clin Invest 1990;86:2071-9.

11. Hirst MA, Hochman HI, Feldman D. Vitamin D resistance and alopecia: A kindred with normal 1.25 dihydroxy vitamin $\mathrm{D}$ binding but decreased receptor affinity for deoxyribonucleic acid. J ClinEndocrinolMetab 1985, 60: 490-5.

12. Hewison $M$, Rut $A R$, KristijanssonK,Walker RE, Dillon MJ, Hughes MR, et al. Tissue resistance to 1,25 -dihydroxy vitamin $\mathrm{D}$ without a mutation of the vitamin D receptor gene. ClinEndocrinol 1993;39:663-70.

13. Sakai Y, Kishimoto J, Demay MB. Metabolic and cellular analysis of alopecia in vitamin $D$ receptor knockout mice. J Clin Invest 2001;107:961-6.

14. Takeda E, Yokota I, Kawakami I, Hashimoto T, Kuroda Y, Arase S. Two siblings with vitamin-D dependent rickets type II: No recurrence of rickets for 14 years after cessation of therapy. Eur J Pediatr 1989;149:54-7.

15. Balsan S, Garabedian M, Larchet M, Gorski AM, Cournot G, Tau C, et al. Long-term nocturnal calcium infusions can cure rickets and promote normal mineralization in hereditary resistance to 1,25-dihydroxyvitamin D. J Clin Invest 1986;77:1661-7.

16. Manandhar DS, Sarkawi S, Hunt MC. Rickets with alopecia-remission following a course of 1-alpha-hydroxy vitamin $\mathrm{D}_{3}$ therapy. Eur $J$ Pediatr 1989;148(8):761-3. 